\title{
XPM-induced degradation of multilevel phase modulated channel caused by neighboring NRZ modulated channels
}

Jensen, Jesper Bevensee; Schiellerup, G.; Peucheret, Christophe; Tokle, Torger; Jeppesen, Palle

Published in:

OFC/NFOEC 2008 - 2008 Conference on Optical Fiber Communication/National Fiber Optic Engineers Conference

Link to article, DOI:

10.1109/OFC.2008.4528082

Publication date:

2008

Document Version

Publisher's PDF, also known as Version of record

Link back to DTU Orbit

Citation (APA):

Jensen, J. B., Schiellerup, G., Peucheret, C., Tokle, T., \& Jeppesen, P. (2008). XPM-induced degradation of multilevel phase modulated channel caused by neighboring NRZ modulated channels. In OFC/NFOEC 2008 2008 Conference on Optical Fiber Communication/National Fiber Optic Engineers Conference (pp. 1-3). IEEE Press. https://doi.org/10.1109/OFC.2008.4528082

\section{General rights}

Copyright and moral rights for the publications made accessible in the public portal are retained by the authors and/or other copyright owners and it is a condition of accessing publications that users recognise and abide by the legal requirements associated with these rights.

- Users may download and print one copy of any publication from the public portal for the purpose of private study or research.

- You may not further distribute the material or use it for any profit-making activity or commercial gain

- You may freely distribute the URL identifying the publication in the public portal 


\title{
XPM-Induced Degradation of Multilevel Phase Modulated Channel Caused by Neighboring NRZ Modulated Channels
}

\author{
Jesper Bevensee Jensen ${ }^{1}$, Gert Schiellerup ${ }^{2}$, Christophe Peucheret ${ }^{1}$, Torger Tokle ${ }^{3}$ and Palle Jeppesen ${ }^{2}$ \\ (1) COM DTU, Technical University of Denmark, Building 343, DK-2800 Lyngby, Denmark \\ Phone: +45 45253877, Fax: +45 45936581, E-mail:jj@com.dtu.dk \\ (2)Tellabs Denmark A/S, Lautrupvang 3C, DK-2750 Ballerup, Denmark \\ (3) OFS Fitel Denmark ApS, Priorparken 680, DK-2605 Brøndby, Denmark
}

\begin{abstract}
The impact of XPM from NRZ modulated channels on an 8-level phase modulated channel in a WDM system was investigated. Requirements on launch power are found. $400 \mathrm{~km}$ transmission was achieved with negligible penalty.
\end{abstract}

2007 Optical Society of America

OCIS codes: (060.4510) Optical communications, 060.1660 Coherent communications, 060.5060 Phase modulation.

\section{Introduction}
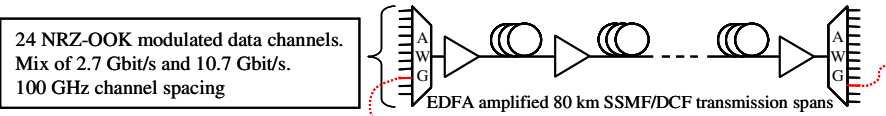

Upgraded channel. $32.1 \mathrm{Gbit} / \mathrm{s}$

RZ-D8PSK modulation at a

symbol rate of 10.7 Gbaud

Fig. 1. The investigated upgrade scenario: A single multilevel modulation upgraded channel in an existing NRZ-OOK WDM system

Multilevel modulation formats have been heavily investigated in recent years due to a combination of high spectral efficiency and good tolerance towards chromatic dispersion (CD). Multilevel modulation can thus be a candidate for increasing the total capacity within a given amplifier bandwidth or it can be used as an upgrade of systems already in use.

When combined with coherent detection and off-line digital signal processing, modulation formats with up to 12 bit per symbol have been reported [1]. These systems have the further advantage of the ability to compensate for $\mathrm{CD}$ and polarization mode dispersion (PMD) in the electronic domain. However, at bit rates above $10 \mathrm{Gbit} / \mathrm{s}$, they require analogue to digital conversion faster than the present state of the art. These systems are therefore more interesting as candidates for next generation installations than for upgrade of already existing installations. Simpler approaches achieving up to 4 bits per symbol using differential detection, and no digital signal processing have been presented in [2-4].

In this paper, we present results of an upgrade experiment where a single channel in a commercial 25 channel WDM system with $100 \mathrm{GHz}$ channel spacing was upgraded from binary non-return to zero (NRZ) on-off keying (OOK) modulation at $10.7 \mathrm{Gbit} / \mathrm{s}$ to return to zero (RZ) $32.1 \mathrm{Gbit} / \mathrm{s}$ differential 8-ary phase shift keying (D8PSK).

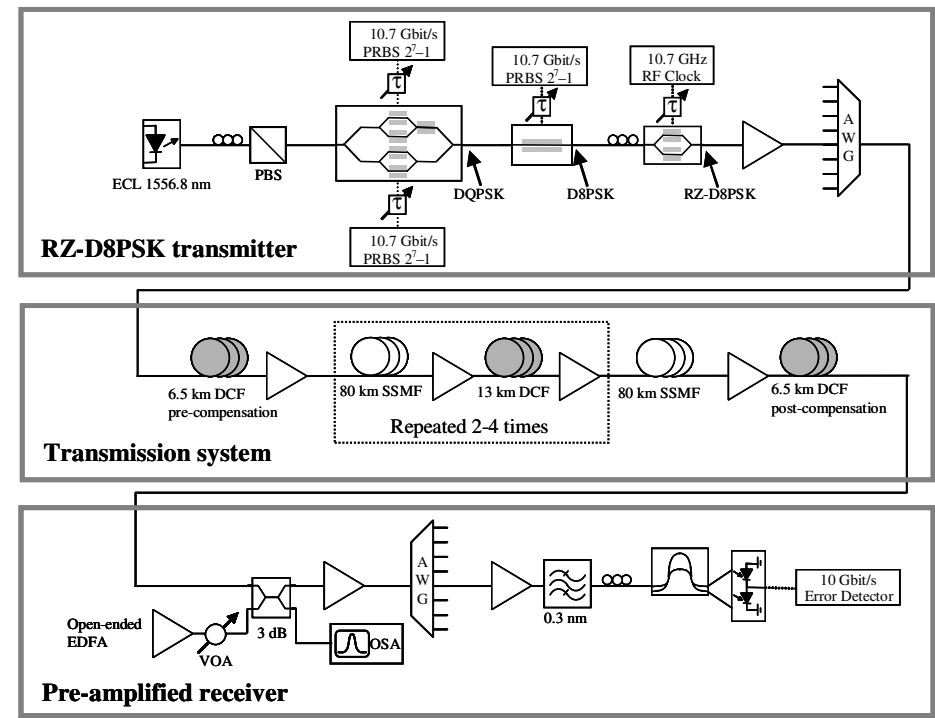

Fig. 2. Simplified block diagram of the setup used in the experiments. 


\section{JThA51.pdf}

The remaining 24 channels were a mixture of $2.7 \mathrm{Gbit} / \mathrm{s}$ and $10.7 \mathrm{Gbit} / \mathrm{s}$ NRZ-OOK channels. Transmission over $400 \mathrm{~km}$ of standard single mode fiber (SSMF) with negligible penalty, however, in order to avoide cross-phase modulation (XPM) induced degradation of the upgrade channel, per channel launch power had to be reduced. Higher XPM tolerance was found when the neighboring channels were phase modulated.

\section{Principle and experimental set-up}

Fig. 2 shows a simplified block diagram of the RZ-D8PSK transmitter (top), the transmission span (middle) and the receiver (bottom). Continuous Wave (CW) light at a wavelength of $1556.8 \mathrm{~nm}$ was phase-modulated by an I/Q modulator (kindly provided by Sumitomo) driven by two de-correlated $10.7 \mathrm{Gbit} / \mathrm{s} 2^{7}-1$ bit long pseudo random bit sequences (PRBS) in order to create a differential quaternary phase shift keyed (DQPSK) signal. Additional phasemodulation was performed by a phase modulator (PM) driven by a third $10.7 \mathrm{Gbit} / \mathrm{s} 2^{7}-1$ bit long PRBS with amplitude equal to $0.25 \mathrm{~V}_{\pi}$ of the PM. The resulting NRZ-D8PSK signal was converted to an RZ-D8PSK signal by a Mach-Zehnder modulator (MZM) driven by a $10.7 \mathrm{GHz}$ electrical clock signal. The total bit-rate is thus 32.1 Gbit/s, corresponding to a data capacity of $30 \mathrm{Gbit} / \mathrm{s}$ after forward error correction (FEC). Modulator loss was compensated by an erbium doped fiber amplifier (EDFA) and the launch power was matched to that of the 24 NRZOOK modulated channels by a variable optical attenuator (VOA), before wavelength division multiplexing by an arrayed wave guide grating (AWG) with $100 \mathrm{GHz}$ channel spacing.

At the pre-amplified receiver, the signal was loaded with amplified spontaneous emission (ASE) noise generated by an open-ended EDFA before wavelength division de-multiplexing by an AWG. The noise level was adjusted by a VOA, and the optical signal to noise ratio (OSNR) in a $0.1 \mathrm{~nm}$ noise bandwidth was determined by an optical spectrum analyzer (OSA). Out of band ASE noise was suppressed by an optical band-pass filter with a $3 \mathrm{~dB}$ bandwidth of $0.4 \mathrm{~nm}$. After optical filtering, the phase information was de-modulated by a 1-symbol delay interferometer, and the signal was detected by a pair of balanced photo-detectors. Bit error ratio (BER) was determined with a programmable error detector, and calculated as one third of the sum of the BER for the four D8PSK tributaries [5].

The transmission system was based on EDFA amplification, $80 \mathrm{~km}$ spans of standard single mode fiber (SSMF) and dispersion compensation after each span with $13 \mathrm{~km}$ dispersion compensating fiber (DCF). Pre-compensation was applied by moving half of the dispersion compensation for the last span to the transmitter Fiber loss was adjusted to $22 \mathrm{~dB}$ per span.

\section{Results and discussion}

A single $10.7 \mathrm{Gbit} / \mathrm{s}$ NRZ-OOK channel was replaced by the $32.1 \mathrm{Gbit} / \mathrm{s}$ RZ-D8PSK upgrade channel. In the commercial system used in these experiments, a launch power of $+2 \mathrm{dBm}$ per channel is normally used. Therefore, initially this launch power was chosen. Fig. 3 (left) shows the BER of the upgrade channel back to back, after $240 \mathrm{~km}$ and after $320 \mathrm{~km}$. The measured OSNR requirement back to back at the FEC limit of BER $=2 \times 10^{-3}$ was approximately $17.5 \mathrm{~dB}$. After $240 \mathrm{~km}$, a penalty of $1.5 \mathrm{~dB}$ was measured, and an overall degradation of the performance is observed as a flattening of the BER curve with increasing OSNR. After $320 \mathrm{~km}$, the penalty at the FEC limit had increased to $2.5 \mathrm{~dB}$, and the overall degradation had increased. This degradation was suspected to be caused by XPM from the neighboring NRZ-OOK channels, and to investigate that, the BER of the upgrade channel after $240 \mathrm{~km}$ was measured as a function of per channel launch power for a fixed OSNR of $24 \mathrm{~dB}$ into the receiver. An optimum launch power of $-1 \mathrm{dBm}$ per channel was found, i.e. $3 \mathrm{~dB}$ lower than what was used in the experiment
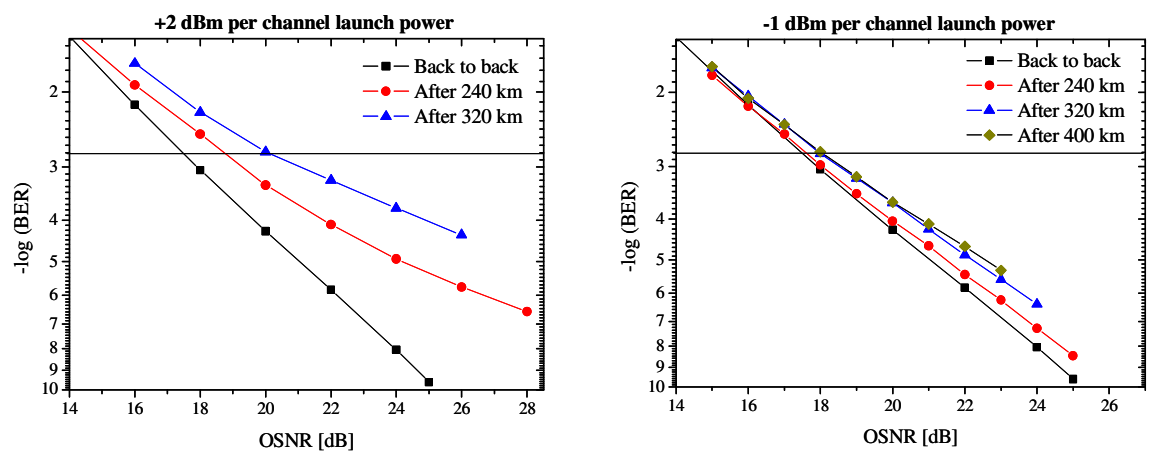

Fig. 3: Measured BER of one $32.1 \mathrm{Gbit} / \mathrm{s}$ RZ-D8PSK channel in a WDM system with 24 NRZ channels. Launch power $+2 \mathrm{dBm}$ per channel (left) and $-1 \mathrm{dBm}$ per channel (right) 


\section{JThA51.pdf}
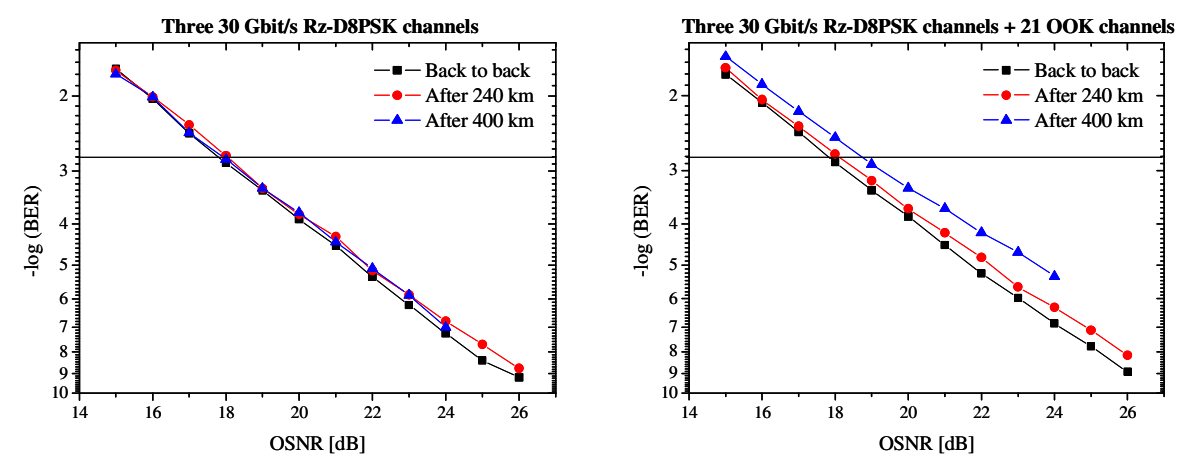

Figure 4: Measured BER of one $32.1 \mathrm{Gbit} / \mathrm{s}$ RZ-D8PSK channel in a WDM system with 2 neighboring RZ-D8PSK channels (left) and with 2 neighboring RZ-D8PSK channels +21 neighboring NRZ channels (right). Launch power: $+0.5 \mathrm{dBm}$ per channel.

thus verifying that the degradation of the upgrade channel was caused by XPM from the neighboring NRZ-OOK modulated channels. In order to test the transmission properties of the upgrade channel when the launch power was kept below the XPM limit, a transmission experiment with a launch power of $-1 \mathrm{dBm}$ per channel was carried out. The BER of the $32.1 \mathrm{Gbit} / \mathrm{s}$ RZ-D8PSK modulated upgrade channel back to back and after $240 \mathrm{~km}, 320 \mathrm{~km}$ and 400 $\mathrm{km}$ transmission is plotted in figure 3 (right). In this case, almost no degradation is observed even after $400 \mathrm{~km}$ with less than $1 \mathrm{~dB}$ penalty at the FEC limit.

The XPM-induced degradation is assumed to be worst from the nearest neighboring channels due to walk-off of channels further away. Further, it is expected that the degradation will be less severe for degrading channels that are only phase modulated rather than for amplitude modulated channels due to the reduced fluctuation in optical power in the fiber. In order to test this assumption, an experiment with three $32.1 \mathrm{Gbit} / \mathrm{s}$ RZ-D8PSK channels was carried out. In this case, the launch power could be optimized for the RZ-D8PSK modulation format. This was done in the same way as described above, and an optimum of $+0.5 \mathrm{dBm}$ per channel was found. The resulting BER of the middle channel back to back, after $240 \mathrm{~km}$ and after $400 \mathrm{~km}$ is plotted in Fig. 4 (left). No degradation is observed, thus verifying the reduced XPM degradation from phase modulated neighboring channels. In order to investigate the influence of extra amplitude modulated channels, 21 NRZ-OOK channels were added to the three RZ-D8PSK channels, and the BER of the central RZ-D8PSK channel was measured with a launch power of $+0.5 \mathrm{dBm}$ per channel. The results are plotted in Fig. 4 (right). A slight degradation is observed after $400 \mathrm{~km}$ with an OSNR penalty of less than $1 \mathrm{~dB}$ at the FEC limit. When compared to Fig. 3 (right), where the launch power was $-1 \mathrm{dBm}$ per channel, we see again that the XPM induced degradation is less severe when the nearest neighboring channels are phase modulated, even in the case of a 25 channel system.

\section{Conclusion}

Different upgrade scenarios using 8 level phase modulation to upgrade individual channels from $10.7 \mathrm{Gbit} / \mathrm{s}$ NRZOOK to $32.1 \mathrm{Gbit} / \mathrm{s}$ RZ-D8PSK in a WDM system with $100 \mathrm{GHz}$ channel spacing have been investigated. For the case of a single channel $32.1 \mathrm{Gbit} / \mathrm{s}$ RZ-D8PSK upgrade and 24 NRZ-OOK modulated channels, $400 \mathrm{~km}$ transmission was achieved with an OSNR requirement of $18 \mathrm{~dB}$ at the BER of $2 \times 10^{-3}$, corresponding to less than $1 \mathrm{~dB}$ penalty compared to the back to back case. However, this result was achieved through a reduction of the launch power from $+2 \mathrm{dBm}$ per channel to $-1 \mathrm{dBm}$ per channel in order to avoid XPM induced degradation. Increased XPM tolerance was achieved when the neighboring channels also were RZ-D8PSK modulated, in which case $400 \mathrm{~km}$ transmission with negligible penalty was achieved with a launch power of $+0.5 \mathrm{dBm}$ per channel.

\section{References}

[1] M. Nakazawa, J. Hongo, K. Kasai and M. Yoshida. Polarization-multiplexed 1 Gsymbol/s, 64 QAM (12 Gbit/s) coherent optical transmission over 150 km with an optical bandwidth of 2 GHz, OFC '07, Paper PDP26, March 2007.

[2] T. Tokle, M. Serbay, J. B. Jensen, Y. Geng, W. Rosenkranz and P. Jeppesen. Investigation of multilevel phase and amplitude modulation formats in combination with polarisation multiplexing up to $240 \mathrm{Gbit} / \mathrm{s}$, IEEE Photonics Technology Letters, vol. 18, no. 20, pp. 2090-2092, October 2006.

[3] T. Tokle, M. Serbay, W. Rosenkranz and P. Jeppesen. 32.1 Gbit/s InverseRZ-ASK-DQPSK modulation with low implementation penalty, LEOS'06, Paper WH2, October 2006.

[4] J. B. Jensen, T. Tokle, C. Peucheret and P. Jeppesen. Transmission of multilevel 60 Gbit/s polarization multiplexed RZ-D8PSK using only 10 Gbit/s equipment, OFC'07, Paper OWM4, March 2007.

[5] Cheolhwan Kim and Guifang Li, Direct-detection optical differential 8-level phase-shift keying (OD8PSK) for spectrally efficient transmission, Optics Express vol. 12, no. 15, pp. 3415-3421, July 2004. 